\title{
La declaración de caducidad de los derechos
}

de aprovechamiento de recursos naturales renovables en el Perú y su problemática Expiration Statement on the Rights of Renewable Natural Resources Use in Peru and its Problems

Carlos Ponce Rivera* http://dx.doi.org/10.21503/lex.v12i13.42

* Magíster en Derecho Constitucional, doctorando en Derecho. Especialista en Derecho Administrativo y Constitucional. carlosponcerivera@gmail.com 


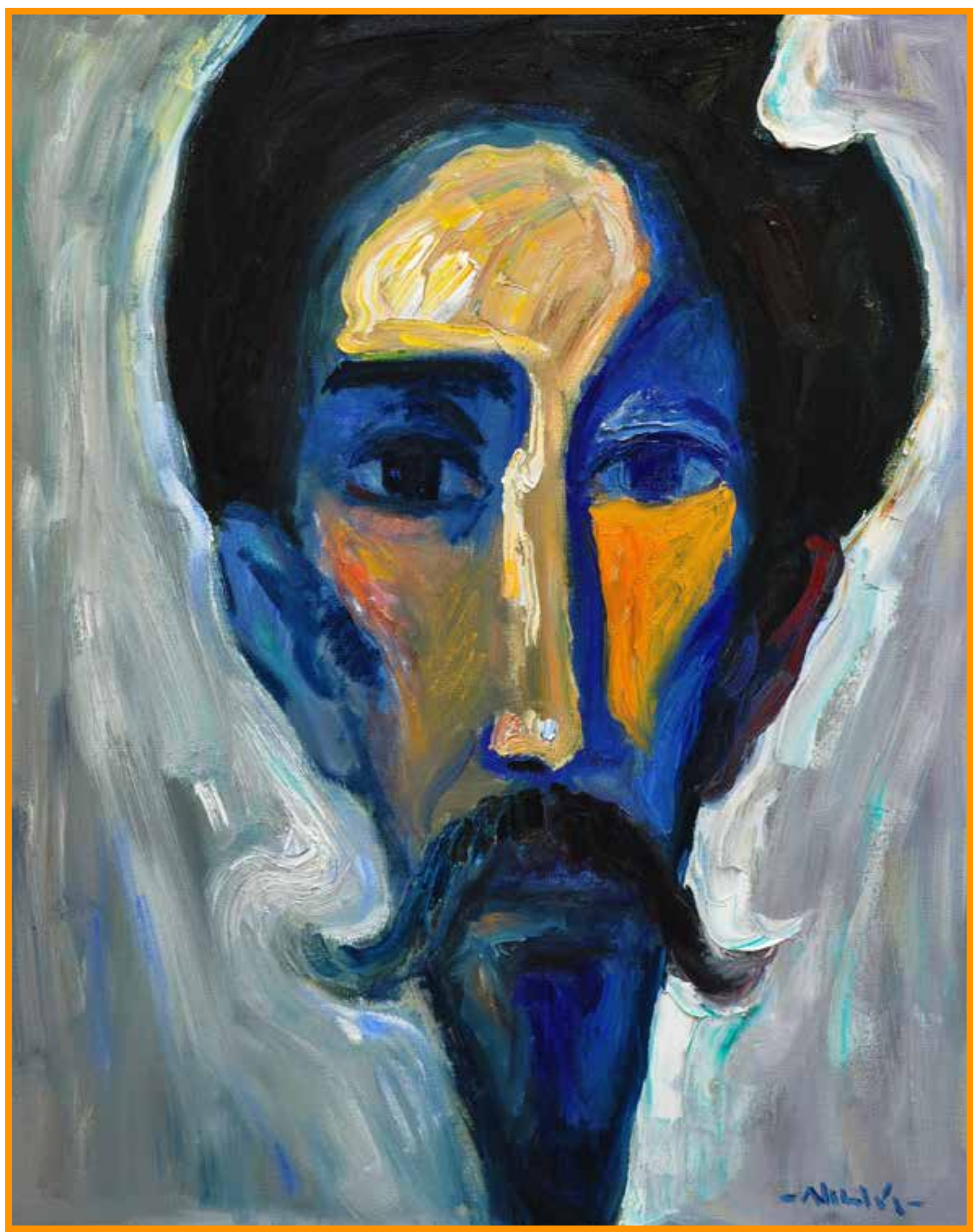

Quijote. Óleo sobre tela $(60 \times 50 \mathrm{~cm})$. 


\section{RESUMEN}

La problemática de la declaración de la caducidad en el Derecho Administrativo está determinada por la dificultad para declararla por ser una determinación unilateral de parte del Estado en virtud del ejercicio de su ius imperium. Parte de esa problemática estriba en la discusión acerca de la naturaleza misma del contrato de concesión, que puede ser conceptualizada de diferentes maneras, y por la discusión referida a la consideración de la caducidad del derecho de aprovechamiento, como una sanción o una medida complementaria; de la toma de posición en ambos temas dependerá cómo es que la administración actúa frente a la necesidad de proteger un bien nacional, como es el recurso forestal, sin vulnerar los derechos de las personas en cuanto concesionarios. Por ello, resulta necesario establecer un criterio claro para conceptualizar las instituciones antes mencionadas, y esta necesidad se torna urgente cuando el Estado viene intentando redefinir su rol en el campo de la explotación de los recursos naturales renovables y cuando se torna cada vez más necesaria su intervención como supervisor y fiscalizador del aprovechamiento de recursos naturales, tal como lo señala el artículo $66^{\circ}$ de la Constitución Política del Estado.

Palabras clave: concesión, caducidad, sanción, razonabilidad, proporcionalidad.

\section{ABSTRACT}

The problem of the expiration statement in Administrative Law is determined by the difficulty to declaring to be a unilateral determination by the State pursuant to the exercise of its ius imperium. Part of the problem lies in the discussion about the nature of the concession contract which can be conceptualized in different ways and the discussion referred to consideration of expiration of use rights as a penalty or a complementary measure. Taking position on both issues will depend on how it is that the administration acts against the need to protect a national asset like the forest resource without violating the rights of individuals as authorized dealers. Therefore, it is necessary to establish clear criteria for conceptualizing the aforementioned institutions and this need becomes urgent when the State is trying to redefine its role in the field of exploitation of renewable natural resources and when intervention becomes increasingly necessary as supervisor and oversight of utilization of natural resources as stated in Article 66 of the Political Constitution.

Key words: concession, expiration, penalty, reasonableness, proportionality. 



\section{Planteamiento del problema}

La Constitución Política del Estado en su artículo $66^{\circ}$ prescribe que los recursos naturales son patrimonio de la Nación y que el Estado es soberano en su aprovechamiento. ${ }^{1}$ Los recursos naturales son todos aquellos elementos que existen en la naturaleza y que son utilizados por el hombre para distintos fines, y pueden ser, siguiendo un criterio de clasificación tradicional, renovables y o renovables; los segundos son aquellos que luego de su aprovechamiento y de un proceso de regeneración natural o artificial pueden ser utilizados nuevamente, como sucede con los recursos de origen vegetal, los cuales pueden regenerarse para ser nuevamente aprovechados luego de un determinado tiempo. ${ }^{2}$ En el Perú, la definición de recurso natural es dada por el artículo $3^{\circ}$ de la Ley Orgánica para el Aprovechamiento Sostenible de los Recursos Naturales Ley $\mathrm{N}^{\circ} 26821$, que señala que se consideran recursos naturales a todo componente de la naturaleza susceptible de ser aprovechado por el ser humano para la satisfacción de sus necesidades y que tenga un valor actual o potencial en el mercado.

En el Perú, de acuerdo con el texto constitucional, el aprovechamiento de los recursos naturales debe ser realizado por particulares bajo la modalidad de concesión. La concesión, como lo señala el artículo $66^{\circ}$ de la Constitución Política del Estado de 1993, otorga a su titular un derecho real sujeto a lo dispuesto por la ley, en este caso la Ley Orgánica para el

1 El artículo $4^{\circ}$ de la Ley Forestal y de Fauna Silvestre Ley N 29763 (ley aprobada en 2011 pero que no está en vigencia por no tener reglamento) señala que el patrimonio forestal y de fauna silvestre de la Nación está constituido por los ecosistemas forestales y otros ecosistemas de vegetación silvestre, los recursos forestales y de fauna silvestre mantenidos en su fuente, la diversidad biológica forestal y de fauna silvestre, incluyendo sus recursos genéticos asociados, los bosques plantados en tierras del Estado, los servicios de los ecosistemas forestales y otros ecosistemas de vegetación silvestre, las tierras de capacidad de uso mayor forestal y tierras de capacidad de uso mayor para protección, con bosques o sin ellos, los paisajes de los ecosistemas forestales y otros ecosistemas de vegetación silvestre en tanto sean objeto de aprovechamiento económico.

2 La Ley Forestal y de Fauna Silvestre vigente en el Perú, Ley $N^{\circ} 27308$, señala que constituyen recursos forestales los bosques naturales, plantaciones forestales y las tierras cuya capacidad de uso mayor sea de producción y protección forestal y los demás componentes silvestres de la flora terrestre y acuática emergente, cualquiera sea su ubicación en el territorio nacional. Dicha definición es repetida en el artículo $5^{\circ}$ de la Nueva Ley Forestal y de Fauna Silvestre Ley $N^{\circ}$ 29763. 
Aprovechamiento Sostenible de los Recursos Naturales Ley Nº 26821.

La concesión es un acto jurídico que tiene por finalidad hacer que un particular pueda explotar el recurso, beneficiándose de él pero bajo ciertas condiciones que están establecidas en la ley y en el título mismo, el cual tiene por finalidad reconocer el derecho de aprovechamiento y al mismo tiempo garantizar su aprovechamiento sostenible; para ello, en el caso de los recursos forestales, el Estado ha formulado mecanismos para la elaboración de instrumentos de gestión donde se precisan las actividades a realizarse a largo y corto plazo. Estos son el Plan de Manejo Forestal (PMF) y el Plan Operativo Anual (POA).

Dentro de los términos para la elaboración de estos instrumentos de gestión, se distinguen actividades que generan impactos en el bosque, esto es, el sistema de aprovechamiento, el mismo que debe considerar los métodos de Aprovechamiento de Impacto Reducido (AIR), que implica una serie de técnicas para evitar dañar al mínimo el ecosistema forestal existente en la zona. Sin embargo, el simple hecho de hacer una intervención en el bosque genera impactos que se busca minimizar mediante planes preventivo correctores y mitigación de los impactos negativos. Tales planes se encuentran también inmersos en los planes de manejo.

Asimismo, un factor importante es la implementación de las actividades silviculturales que se detallan tanto en el PMF como en el POA, ya que al aplicarlas se busca la producción constante de las especies comerciales, a través de su favorecimiento.

Sin embargo, a pesar de saber que se gana mucho con aplicar el aprovechamiento forestal sostenible, hoy en día las concesiones forestales vigentes tienen un común denominador, y ese es el incumplimiento de las actividades que ellos mismos establecen en sus planes de manejo forestal.

Durante el período 2010-2012, en el Perú, el Organismo de Supervisión de los Recursos Forestales y de Fauna Silvestre (OSINFOR), órgano de nivel nacional encargado de fiscalizar el cumplimiento de las obligaciones contractuales establecidas en los contratos de concesión forestal, ha caducado concesiones que abarcan un área de 742 395,01 hectáreas de bosques de producción en 5 regiones (ver cuadro No 01). Esta declaración es resultado de un procedimiento administrativo sancionador conocido como PAU, en el cual se discute sobre la existencia de causales para su declaración, pudiendo además contener imputaciones referidas a la comisión de infracciones administrativas, las cuales están tipificadas en el artículo $363^{\circ}$ de la Ley Forestal y de Fauna Silvestre Ley N ${ }^{\circ}$ 27308. Las causales de caducidad están establecidas en el artículo $18^{\circ}$ de la Ley Forestal y de Fauna Silvestre, (LFFS) Ley N $^{\circ} 27308$ y su reglamento (RLFSS), así como en los diferentes contratos aprobados por resoluciones jefaturales del antiguo INRENA a partir del año 2002. 
Cuadro 1. Superficie de concesiones caducadas en el período enero 2010- junio 2012

\begin{tabular}{|l|l|}
\hline Región & Área (ha) \\
\hline Huánuco & 6086,41 \\
\hline Loreto & 246596,38 \\
\hline Madre de Dios & 138597,79 \\
\hline San Martín & 110400,81 \\
\hline Ucayali & 240713,62 \\
\hline Total & 742395,01 \\
\hline
\end{tabular}

Fuente: OSINFOR 2012, elaboración propia.

Algunas de las causales para declarar la caducidad de un derecho de aprovechamiento son bastante generales por cuanto, por ejemplo, en el artículo $18^{\circ}$ de la Ley $\mathrm{N}^{\circ} 27308$ Ley Forestal y de Fauna Silvestre se señala como una de ellas el incumplimiento de las condiciones establecidas para la modalidad de contrato, lo cual puede llevar a pensar que cualquier incumplimiento puede generar su extinción, determinando que esta declaración constituya una medida discrecional al no establecerse en la norma elementos para su evaluación, siendo necesaria, por esa razón, la existencia de criterios mínimos para considerar su aplicación. La nueva Ley Forestal y de Fauna Silvestre Ley N ${ }^{\circ} 29763$ no ha contribuido mucho a solucionar este aspecto, por cuanto en su artículo $153^{\circ}$ señala que constituye causal de caducidad el causar severos perjuicios que pongan en grave riesgo el ambiente y la biodiversidad de acuerdo a la normativa vigente, lo cual, aun cuando es un poco más específico que la redacción vigente porque exige la existencia de daño para su declaración, deja siempre en manos de la administración la evaluación de la gravedad; es más, el mismo artículo incorpora como causal de caducidad el incumplimiento de los compromisos de inversión acordados para el otorgamiento del título habilitante, lo cual lleva a pensar en el hecho de que cualquier incumplimiento, sin importar su magnitud u objeto, puede implicar su declaración.

La caducidad tiene, además de la problemática derivada del considerarla como una sanción administrativa, un criterio que puede llevar a pensar que su declaración, cuando es acompañada de la imposición de una multa por una conducta que también constituye una infracción (como la extracción ilegal de madera o el cambio de uso del suelo), es una violación del principio-derecho del non bis in ídem así como del hecho de poder invocar la prescripción de la causal por haber transcurrido el tiempo máximo para determinar su existencia por parte del Estado.

Además, existe el problema derivado de la determinación de causales establecidas únicamente en el contrato de concesión y no en la Ley o su reglamento así como su modificación unilateral, por lo que se puede considerar que tal consideración representa 
una violación del principio de legalidad que implica que toda sanción debe estar establecida expresamente en una norma con rango de ley así como también del principio de jerarquía normativa, siendo por tanto inconstitucional y por ello no invocable por la administración, así como también una violación del principio de seguridad jurídica al modificar las causales establecidas en la ley al momento de la firma del contrato sin mediar la autorización del concesionario, como efectivamente ha sucedido en varias oportunidades mediante la emisión de Decretos Supremos que constantemente han ido modificando las causales de caducidad establecidas en el Reglamento de la Ley Forestal y de Fauna Silvestre vigente, como también con la emisión de la nueva ley (29763) que deja sin efecto la anterior y que considera causales no establecidas como tales en la legislación actualmente vigente.

La importancia de considerar esta problemática radica no solo en que tiene que ver directamente con la protección de los recursos naturales existentes principalmente en la Amazonía, los cuales están bajo constante amenaza, sino en sus implicancias económicas y sociales, por cuanto el comercio de la madera moviliza en el Perú anualmente 800 millones de dólares aproximadamente, cifra que no incluye lo movilizado ilegalmente a través del blanqueo de guías u otros mecanismos ilícitos o informales que son la causa de la crisis que afronta actualmente el sector forestal en el Perú y que ha llevado a incluir el tema inclusive en el Tratado de Complementación Económica firmado entre el Perú y los Estados Unidos de América en un acápite especial, en donde se pone de manifiesto la preocupación por salvaguardar el patrimonio que se considera que no solo es de los peruanos sino de toda la humanidad.

\section{El contrato de concesión}

La concesión administrativa es el medio más eficaz, dentro del Estado moderno, para entregar a los particulares ciertas actividades o la explotación de recursos nacionales que la administración pública no está en condiciones de desarrollar ya sea por incosteabilidad económica, por impedimentos jurídicos, organizacionales propios o por inconveniencia política. Las concesiones, siguiendo a Dromi, se constituyeron en herramientas de participación de la actividad privada en la prestación de cometidos públicos, como categorías de los contratos de transformación [...] estos nuevos contratos se erigieron en los instrumentos que coadyuvaron a la relocalización del Estado ${ }^{3}$.

Las concesiones son los instrumentos que sirvieron al Estado para sustituir la economía de Estado por la economía de mercado luego del fracaso de los modelos intervencionistas y de la unipolarización de la economía a partir de la caída del Muro de Berlín a finales de la década de 1980, sirviendo como elemento para transformar al Estado acentuando la nota

3 Roberto Dromi. Derecho Administrativo. Décima edición. Buenos Aires, 2004, p. 471. 
de colaboración del contratista en el logro del bien común, ya que los contratos públicos, además de constituirse en herramienta del programa general de gobierno, colaboraron en la edificación de un nuevo modelo de Estado.

Estos contratos, que instrumentaron el traspaso de cometidos del Estado a manos privadas, no se limitaron a establecer el contenido de la obligación o la prestación objeto del contrato. Determinaron también las condiciones en que debían desenvolverse las prestaciones, las metas de calidad y extensión del servicio a alcanzar, las inversiones a realizar, la modernización y permanente actualización de los medios materiales y técnicos afectados a la prestación, las tecnologías a utilizar.

El Estado cambió su rol, transfiriendo la responsabilidad directa de la prestación, pero reteniendo la regulación y el control de las variables de cumplimiento del contrato. En las mismas incidían elementos políticos, económicos, jurídicos y sociales, y el Estado debe estar presente, regulando, controlando, asegurando y garantizando los derechos y obligaciones de los protagonistas del servicio: prestadores y usuarios. Ello explica la relevancia que adquirió la defensa de los consumidores y de los usuarios y de la competencia. ${ }^{4}$

La palabra concesión, según Báez Martínez,

proviene del latín consesio, derivado de concedere, que significa conceder; además es un término genérico que califica diversos actos mediante los cuales la administración confiere a personas privadas ciertos derechos o ventajas especiales sobre el dominio del Estado o respecto del público mediante sujeción a determinadas cargas y obligaciones; la mayoría de las veces, tales derechos y ventajas complementan el ejercicio de ciertas prerrogativas administrativas. ${ }^{5}$

Según el Diccionario de Derecho Público, de Emilio Fernández Vásquez, la concesión es el acto administrativo por medio del cual la administración, en virtud de facultades o atribuciones derivadas del ordenamiento jurídico, confiere a una persona un derecho o un poder que antes no poseía; o también un acto de Derecho público que confiere a una persona un derecho o poder del que antes carecía, mediante la trasmisión a ella de un derecho o del ejercicio de un poder propio de la administración. ${ }^{6}$

Para Cano Jiménez,

La concesión es un acto administrativo público por medio del cual el Estado, llamado concedente, faculta al particular, llamado concesionario, para que administre y explote en su provecho, en forma particular y continua, pero por tiempo determinado, bienes de dominio

4 Ibidem. p. 471-472.

5 Roberto Báez Martínez. Manual de Derecho Administrativo. México: Ed. Trillas, 1990, p. 220.

6 Emilio Fernández Vásquez. Diccionario de Derecho Público. Buenos Aires: Astrea, 1981, p. 767. 
público o servicios públicos, en vista de satisfacer un interés colectivo, mediante una ley preconcebida y un contrato formulado entre las partes. ${ }^{7}$

Para Enrique Pérez de León, la concesión es el aprovechamiento, por parte de los particulares, de la explotación de un servicio público o de bienes que forman parte del Estado. Es el acto jurídico que tiene por objeto otorgar a un particular un poder jurídico sobre una manifestación de la administración pública; o un bien, como los actos del poder público que dan facultades a los particulares para el establecimiento y explotación de un servicio público o para la explotación y aprovechamiento de bienes del dominio directo y de propiedad de la Nación; o también como el procedimiento por el cual una persona pública denominada autoridad concede y confía a una persona física o moral, llamada concesionario, el cuidado de manejar un servicio público, bajo el control de la autoridad concedente, mediante una remuneración que generalmente consiste en las cuotas que el concesionario percibirá de los usuarios del servicio; o por último, como la gracia o merced que el Estado otorga a un particular para crear un derecho tolerado, o para permitir su ejercicio, ya sea que el Estado lo otorgue en la forma espontánea o a solicitud del particular. ${ }^{8}$

Para Serra Rojas, la concesión es un acto administrativo por medio del cual la Administración Pública Federal confiere a una persona una condición o poder jurídico para ejercer ciertas prerrogativas públicas con determinadas obligaciones y derechos para la explotación de un servicio público, de bienes del Estado o los privilegios exclusivos que comprenden la propiedad industrial. ${ }^{?}$

$\mathrm{Al}$ respecto, es necesario anotar la clasificación que Rodríguez Arana realiza respecto de las clases de concesiones al diferenciar la concesión de servicio público y la concesión de dominio público (conocida también como demanial), al señalar que la primera sí es un contrato, en tanto que la segunda constituye un acto unilateral de parte del Estado. Considerando lo antes dicho, es necesario dejar establecido que la concesión para el aprovechamiento de recursos forestales constituye un acto jurídico de naturaleza administrativa que produce auténticos derechos reales administrativos teniendo por objeto la administración y aprovechamiento de recursos naturales que son patrimonio de la Nación. Al ser un acto de naturaleza administrativa, está llevado por los principios generales aplicables al Derecho Público, entre ellos el de la primacía del interés público y el de la subordinación de la voluntad del administrado a la del Estado, que siempre tiene una posición de privilegio en la relación contractual.

\footnotetext{
Sergio Cano Jiménez. "Estudio sobre la concesión administrativa y su definición". Revista del Poder Judicial del Estado de Guanajuato, 1 (1964), p. 54.

8 Enrique Pérez de León. Notas de Derecho Constitucional y Administrativo”. 14 ed. México: Porrúa, 1993, p. 285.

9 Andrés Serra Rojas. Derecho Administrativo. T. 1., 9na. ed. México, 1979, p. 226.
} 
En el Perú, la legislación no establece cuál es la naturaleza de la concesión demanial sino que se limita a establecer sus características y límites. Así, el artículo $23^{\circ}$ de la Ley para el Aprovechamiento Sostenible de los Recursos Naturales Ley No 26821 establece que la concesión, aprobada por las leyes especiales, otorga al concesionario el derecho para el aprovechamiento sostenible del recurso natural concedido, en las condiciones y con las limitaciones que establezca el título respectivo; señala además que la concesión otorga a su titular el derecho de uso y disfrute del recurso natural concedido y, en consecuencia, la propiedad de los frutos y productos a extraerse, y puede ser otorgado a plazo fijo o indefinido, estableciendo además un régimen de estabilidad jurídica al señalar que es irrevocable en tanto el titular cumpla las obligaciones que esta Ley o la legislación especial exijan para mantener su vigencia, pudiendo ser objeto de disposición, hipoteca, cesión y reivindicación. Dicha norma deja a la ley especial la regulación de cada derecho según el recurso entregado, señalando además que será esta la que defina en última instancia la naturaleza del derecho de aprovechamiento así como sus alcances y limitaciones, debiendo contemplar en forma precisa los atributos que se conceden, sean estos de carácter real o de otra naturaleza, lo cual termina siendo una aparente contradicción con lo señalado en el artículo $66^{\circ}$ de la Constitución Política de 1993, que señala que la concesión otorga un derecho real sin dejar espacio para que se puedan considerar derechos de "otra naturaleza". Lo que sucede es que el legislador ordinario va más allá de lo señalado por el constituyente al momento de legislar, por cuanto reconoce derechos de aprovechamiento diferentes a la concesión y que, por tanto, tienen diferente naturaleza, lo cual se justifica en razones prácticas ya que en la realidad no toda modalidad de aprovechamiento necesita de una concesión para desarrollarse, tal como sucede con los recursos forestales, los cuales, bajo la Ley $\mathrm{N}^{\circ} 27308$, pueden ser aprovechados en tres modalidades: concesión, permiso o autorización. Dicha norma señala en su artículo $60^{\circ}$ que los títulos habilitantes son actos de naturaleza administrativa mediante los cuales el Estado otorga a particulares el derecho de aprovechamiento de los recursos forestales y de fauna silvestre, así como el derecho a los beneficios económicos procedentes de los servicios de los ecosistemas que se desprendan de su manejo, determinando además los mecanismos de acceso y las variantes que se pueden presentar, estableciendo las causales de caducidad del derecho de aprovechamiento.

La redacción de la norma evidencia que el legislador era consciente de lo difícil que es determinar la verdadera naturaleza de la concesión, por lo que optó por una fórmula general cuyo único aporte es establecer qué es un acto jurídico regulado por normas de Derecho Público, lo cual además conceptualmente parece estar claro, sea cual sea la postura que se tome con relación a la naturaleza del acto. Sin embargo, queda por aclarar qué se debe entender por "acto de naturaleza administrativa", por cuanto dentro de esta definición encaja el acto administrativo y el contrato administrativo, siendo ambos expresión de la voluntad del Estado, pero diferenciados por la unilateralidad de uno y la bilateralidad del otro; en 
efecto, Dromi señala que "las decisiones administrativas se expresan a través de operaciones materiales y también mediante declaraciones intelectuales de origen unilateral o bilateral, de alcance individual o general y de efectos directos o indirectos". ${ }^{10}$

Dentro de las decisiones administrativas señaladas por Dromi se encuentran el acto administrativo, el contrato administrativo y el reglamento así como los actos de administración directa que, sin llegar a constituir actos administrativos, son también expresión de la función administrativa del Estado; en ese sentido, como se tiene dicho, la regulación no aporta mucho, debiendo por tanto establecer vía análisis doctrinario su real naturaleza para poder determinar sus alcances y con ellos las limitaciones del Estado en su regulación y el ámbito del ejercicio de los derechos que ella otorga al concesionario.

Esto es así porque la conceptualización de la concesión como un acto administrativo no es pacífica, porque en la doctrina y la jurisprudencia existen posturas encontradas al respecto, puesto que algunas consideran a la concesión como un contrato, es decir, como un acto bilateral, mientras otros lo tienen como un acto unilateral o como un acto mixto. El motivo para la existencia de estas posiciones radica en cómo la concesión se materializa formalmente, es decir, el procedimiento para su otorgamiento. En efecto, la concesión siempre se va a materializar a partir de una decisión unilateral del Estado, que determina, por razones de necesidad política o exigencia jurídica, su otorgamiento, estableciendo unilateralmente las condiciones para ello, es decir, estableciendo el recurso a concesionar, el mecanismo de otorgamiento, las características del futuro concesionario, sus derechos y obligaciones, las sanciones por incumplimiento, los mecanismos para establecerla y, en resumen, todo aquello que se considere necesario para regular sin realizar ninguna negociación la actividad, porque se entiende que el proceso de elaboración de bases es previo al concurso. Sin embargo, para que la concesión se pueda materializar, siempre es necesaria la participación del concesionario, quien con su firma va a exteriorizar su consentimiento y aceptación de las condiciones que le son impuestas y va a determinar la generación de la relación jurídica con el Estado, y con ello el establecimiento de una relación de dependencia con relación a este al pasar a tener una condición jurídica diferente, lo cual lleva a denominar al título como "contrato", noción que trae consigo la noción de bilateralidad del acto jurídico.

Si se considera como válida la primera postura, o sea aquella que considera a la concesión como un contrato, se estaría ante la idea de la imposibilidad de modificar términos contractuales que han sido sometidos a la voluntad de las dos partes por simple decisión del Estado. Sin embargo, hay que considerar que no estamos ante cualquier tipo de contrato sino ante un contrato administrativo que tiene características diferentes a las del contrato civil, el cual efectivamente se caracteriza por la imposibilidad de modificar términos contractuales

10 Roberto Dromi. Op. cit. p. 353. 
sin la participación de las partes firmantes. En los contratos administrativos, los principios de la autonomía de la voluntad e igualdad jurídica de las partes quedan subordinados[...] en este sentido puede decirse que la libertad de las partes queda circunscripta o limitada por la norma que fija el procedimiento para elegir al contratista, la aprobación o autorización legislativa o administrativa, y la subordinación del objeto al interés público. El contratista no tiene, en principio, la libertad de disentir respecto de las condiciones del contrato; solo puede aceptar o rechazarlas, prevaleciendo siempre el interés público sobre los intereses privados. En consecuencia, las prerrogativas de la Administración se manifiestan en la desigualdad jurídica en relación con sus contratistas y en las cláusulas exorbitantes del Derecho común.

Las partes están en un plano de desigual. En los contratos administrativos desaparece el principio de igualdad entre las partes, uno de los elementos básicos de los contratos civiles. La Administración aparece en una situación de superioridad jurídica respecto del contratista.

Cuando una de las partes contratantes es la Administración, se imponen ciertas prerrogativas y condiciones que subordinan jurídicamente al contratista. El principio de la inalterabilidad de los contratos no puede ser mantenido, sino que cede ante el ius variandi que tiene la Administración a introducir modificaciones en ellos, y que son obligatorias, dentro de los límites de la razonabilidad para el contratista.

Esta desigualdad jurídica se traduce en la competencia que tiene la Administración para: 1) Adaptar el contrato a las necesidades públicas, variando dentro de ciertos límites las obligaciones del contratista (modificación unilateral, mutabilidad del contrato). Es decir que el contrato administrativo carece de la rigidez e inmutabilidad del contrato civil, porque cede ante el interés público; 2) Ejecutar el contrato por sí o por un tercero en caso de incumplimiento o mora del contratista, en forma directa, unilateral y por cuenta de este (ejecución con sustitución del contratista); 3) Dejar unilateralmente el contrato sin efecto en caso de incumplimiento, cuando las necesidades públicas lo exijan (rescisión contractual). ${ }^{11}$

Si se considera la segunda, o sea la que considera a la concesión como un acto administrativo, se va a considerar siempre la posibilidad de cambiar su contenido en virtud a que siendo un acto unilateral y de liberalidad por parte del Estado que actúa soberanamente, abre el espacio para que, tal como lo señala Olivera Toro, citado por Calafell, por su situación de privilegio el Estado pueda "modificar o revocar el régimen a que está sujeta la concesión, cuando así lo exija el interés público". ${ }^{12}$ En cuanto a la tercera posición, considera a la concesión como un acto mixto porque en esta interviene, en una primera fase, la voluntad unilateral del Estado al reglamentar el proceso y las condiciones del otorgamiento de la concesión, y, en una segunda,

11 Roberto Dromi. Op. cit. p. 483-484.

12 Jorge Calafell. "Teoría general de la concesión”. Jurídica. Recuperado el 25 de septiembre de 2013 desde http://www. juridicas.unam.mx/publica/librev/rev/jurid/cont/26/pr/pr19.pdf 
la voluntad consensuada al momento de aceptar el concesionario las condiciones establecidas en el contrato, y termina siempre por reconocerse la dependencia de la segunda con respecto a la primera, ${ }^{13}$ esto por la finalidad que persigue la concesión (interés público) y porque en ella siempre va a intervenir el Estado como otorgante.

El acto reglamentario fija las normas a que ha de sujetarse la organización y funcionamiento del servicio, y dentro de él quedan comprendidas las disposiciones referentes a horarios, tarifas, modalidades de prestación de servicio, derechos de usuarios, etc.

Como ya lo hemos indicado, la administración tiene la facultad de variar las condiciones en cualquier momento, de acuerdo a las necesidades que se deban satisfacer con el servicio, sin que intervenga el conocimiento del concesionario. ${ }^{14}$

Esto se debe a que la concesión, en cualquiera de sus clases, siempre va a estar motivada por el interés público porque siempre está enmarcada en la búsqueda de un interés colectivo siendo además un acto discrecional, ya que la autoridad a la que se dirige la solicitud de concesión se encuentra en la completa libertad de elegir, de conformidad a los elementos contenidos en la ley, a la persona de derecho privado cuya propuesta sea la más atractiva y adecuada a las necesidades de la administración. ${ }^{15}$

Para efectos de la extinción del contrato, es necesario recordar, siguiendo siempre a Rodríguez Arana, que existen diversos tipos de concesión por cuanto

no será lo mismo caducar una concesión por falta de la prestación convenida y que se produce con relación al término previsto en la cláusula concesional de conformidad con la naturaleza de negocio fijo atribuida al contrato administrativo que construirla sobre el incumplimiento de la condición aceptada por el destinatario del acto administrativo, ${ }^{16}$ lo cual implica que las causales y forma de extinción del contrato no operan de la misma manera sino en función del tipo de acto que se está extinguiendo, por cuanto el primer supuesto se aplica para las concesiones de prestación de servicio público, y el segundo para las concesiones de bien público como las de explotación de recursos naturales.

13 Ambas posiciones no son contradictorias en este punto por cuanto el contrato administrativo también está determinado por la prevalencia de los intereses públicos frente a los privados, lo cual lleva a considerar la existencia de una posición de privilegio o superioridad del Estado en la relación caracterizada por la existencia de la cláusula exorbitante del derecho común que se extiende a la interpretación, modificación y resolución del contrato.

14 Jorge Calafell. Op. cit. p. 217.

15 Alejandro de la Fuente Alonso. "La naturaleza jurídica de la concesión administrativa". Recuperado desde http://portal. veracruz.gob.mx/pls/portal/docs/page/colver/difusion/revista_conciencialrevistano.8/2.-alejandro\%20de\%20la\%20fuente\%20 alonso.pdf

16 Jaime Rodríguez Arana. "Reflexiones sobre la caducidad en el Derecho Público". Separata de la Revista Aragonesa de Administración Pública, 5, 1994, p. 346. 
3. Los términos contractuales y la posibilidad de modificar las causales de extinción de la concesión no establecidas en la ley

Definida la institución en general, queda por ver, en segundo término, los aspectos particulares vinculados a la extinción del contrato de concesión forestal. Una de esas particularidades es la referida a la posibilidad de modificar las condiciones de extinción en el contrato, incorporando nuevas cláusulas o modificando aquellas existentes en la ley.

En ese sentido, tal como se ha señalado antes, considerando que la concesión administrativa de bien público es un acto de naturaleza mixta en el cual siempre la voluntad del Estado va a ser determinante y que este va a estar en una posición de privilegio frente al concesionario, se concluye que el contrato puede incluir cláusulas que contengan condiciones no establecidas en la ley o en el reglamento, ello considerando siempre la finalidad del acto mismo, cual es el interés público, por lo que el principio de legalidad no es vulnerado porque a pesar de que los términos contractuales son aprobados por una norma reglamentaria —en el caso de estudio una Resolución Jefatural del ex INRENA—, siempre antes de su vigencia está de por medio la manifestación de voluntad del concesionario, es decir, su consentimiento, el cual va a determinar que la persona que lo da se obligue a cumplir todo lo señalado en el contrato, lo que implica además el sometimiento voluntario a las reglas establecidas en dicho documento, entre las cuales se pueden incluir medidas complementarias destinadas a asegurar una adecuada explotación del recurso, pudiendo, de considerarse que estas son excesivas, cuestionarlo ante el órgano jurisdiccional, manteniendo mientras tanto su plena vigencia. Además, considerando lo dicho en el sentido de que el Estado puede variar unilateralmente durante la vigencia del contrato las condiciones en el establecidas, se debe concluir señalando que también puede variarlas antes de su vigencia, por cuanto la resolución que aprueba el contenido de los contratos, aunque de menor jerarquía normativa que la ley o el reglamento, no termina sino siendo también una expresión de la voluntad del Estado en la búsqueda de salvaguardar el interés general.

Así, en el Perú se presenta el caso de que las condiciones contractuales para declarar la caducidad de un derecho de aprovechamiento han ido variando en algunos casos modificando la Ley y en otros el reglamento, beneficiando al concesionario en unos casos y en otros estableciendo cláusulas más gravosas, habiéndose detectado inclusive contratos de la misma modalidad pero con diferente contenido. Para modificar las causales de caducidad, regularmente se ha considerado la utilización de normas reglamentarias como son los Decretos Supremos, el último de los cuales ${ }^{17}$ eliminó una causal de caducidad y otra la convirtió en una mera falta administrativa; o también normas con rango de ley, como el Decreto Legislativo $\mathrm{N}^{\circ} 1100$, que establece una nueva causal de caducidad, o la nueva ley Forestal y de Fauna

17 Decreto Supremo Nº 015-2013-MINAGRI. 
Silvestre, que establece causales diferentes a las señaladas en su antecesora, en ninguno de cuyos casos se consultó al concesionario.

4. Declaración de la caducidad de los derechos de aprovechamiento de recursos forestales y de fauna silvestre, el principio del non bis in idem y la prescripción de la potestad de la administración para su declaración

A diferencia de lo que sucede en el Derecho Civil, la caducidad tiene una naturaleza diferente en el Derecho Administrativo por cuanto con esta denominación se conoce a la declaración de extinción de un derecho otorgado a un particular por una causa sobreviniente previamente establecida en la ley, pudiendo ser producto o no del paso del tiempo, a diferencia de lo que ocurre con la caducidad regulada en el Derecho Civil, en donde el elemento esencial para que esta se produzca siempre va a ser el paso del tiempo; ${ }^{18}$ además, se tiene que la caducidad administrativa siempre debe ser declarada por la Administración, por lo que no es automática, a diferencia de la caducidad civil. Tal como lo señala Rodríguez Arana, la administración no crea el título, no crea la caducidad, simplemente la declara.

El acto administrativo correspondiente no es, en términos comunes, constitutivo, sino declarativo. ${ }^{19}$

Calafell considera a la caducidad dentro de las figuras jurídicas que tienen por efecto la extinción del contrato de concesión administrativa. ${ }^{20} \mathrm{El}$ mismo autor señala que la declaración de la caducidad se va a producir ante el incumplimiento de las obligaciones del concesionario, y que es una sanción de orden público, que se considera inherente a la concesión misma y que nunca podrá dejar de existir si se considera que está de por medio un interés colectivo. ${ }^{21}$

Sin embargo, el término "sanción" debe ser considerado no en el sentido penal de la palabra, por cuanto, conforme se verá más adelante, en sentido estricto no lo es. El mismo Calafell, citando a Garrido Falla señala que la caducidad no es una sanción de tipo penal, solo

18 El Código Civil Peruano de 1894 regula la caducidad de la siguiente forma:

Artículo $2003^{\circ}$.- Efectos de la caducidad

La caducidad extingue el derecho y la acción correspondiente.

Artículo 2004\%.- Legalidad en plazos de caducidad

Los plazos de caducidad los fija la ley, sin admitir pacto contrario.

Artículo $2005^{\circ}$.- Continuidad de la caducidad

La caducidad no admite interrupción ni suspensión, salvo el caso previsto en el artículo 1994. inciso 8.

Artículo 2006.- Declaración de caducidad

La caducidad puede ser declarada de oficio o a petición de parte.

Artículo 2007\%.- Cumplimiento del plazo de caducidad

La caducidad se produce transcurrido el último día del plazo, aunque este sea inhábil.

19 Jaime Rodríguez Arana. Op. cit. p. 345.

20 Jorge Calafell. Op. cit. p. 226.

21 Ibid. 
aplicable en caso de infracción del concesionario, sino una medida de apreciación inexcusable cuando se producen los motivos señalados en la ley, ${ }^{22}$ pudiendo ser esta declarada producto de una conducta culpable del concesionario. Este criterio, sin embargo, no es del todo pacífico por cuanto existe un sector de la doctrina que sí la considera como una sanción. Así por ejemplo, Rodríguez Arana señala que la caducidad ante todo, supone una potestad que se dirige a velar por el incumplimiento de la concesión y, si se producen incumplimientos graves de obligaciones esenciales imputables al concesionario, a iniciar el correspondiente procedimiento administrativo de caducidad. Por tanto, es innegable que supone una reacción del Ordenamiento frente a la conducta del concesionario. Es, pues, una sanción a la actuación del particular concesionario. ${ }^{23}$

La caducidad de una concesión se va a producir, generalmente, por un incumplimiento contractual que es considerado tan grave que impide la consecución del interés público a que está sujeta toda concesión, ${ }^{24}$ nótese que no se está hablando de la imposibilidad de seguir prestando el servicio o aprovechando el bien otorgado en administración; se habla de una afectación al interés público que se considera de tal magnitud que hace imposible que el contrato siga vigente, lo cual quiere decir que no está relacionada simplemente al objeto material sino que está ligada a la consecución del interés público (objeto del contrato), lo que por supuesto trae más de una implicancia, por cuanto el concepto mismo de interés público es siempre difuso por estar vinculado a una noción ideológica del interés general que es, por tanto, subjetiva.

El interés público encuentra siempre su origen en el querer axiológico de los individuos[...] El interés público, en consecuencia, cosa o bien valioso, querido o pretendido por cada individuo, trasunto de la influencia social del pasado y del presente con pretensiones de vigencia para el porvenir, trasmutada por ellos mismos, en un querer predominante que se identifica con el de toda la comunidad, surge como algo en el que cada componente de la sociedad, por retorno, reconoce e identifica su propio querer y su propia valoración positiva. ${ }^{25}$

Para el caso de los contratos de concesión forestal en el Perú, la caducidad se entiende como la conclusión anticipada del título habilitante otorgado por el Estado al administrado para que este pueda, legalmente, aprovechar de manera sostenida los recursos naturales que pertenecen a la Nación. El título habilitante otorga el derecho al administrado para que cumpliendo determinadas condiciones pueda usufructuar $y$, en el caso de los recursos forestales, llegar a extraer determinadas especies, en determinado volumen y número, en un lugar determinado y durante un tiempo determinado

22 Ibid.

23 Jaime Rodríguez Arana. Op. cit. p. 351.

24 Ibid. p. 348.

25 Héctor Escola. El interés público como fundamento del Derecho Administrativo. Buenos Aires: Ed. Depalma, 1989, p. 239. 
Es decir, la caducidad del título habilitante constituye una expresión administrativa de parte del Estado, cuyos efectos recaen en un administrado como consecuencia de su actuar; dicha expresión debe estar precedida de un hecho previo lo suficientemente gravoso y previamente establecido en la ley como para generar su declaración, debiendo evaluarse no solo la intención con la que el agente ha actuado sino principalmente el impacto económico y ambiental de su conducta.

La Ley de Aprovechamiento Sostenible de los Recursos Naturales Ley No 26821 en su artículo $30^{\circ}$ señala:

La aplicación de las causales de caducidad se sujetará a los procedimientos que establezcan las leyes especiales, sin perjuicio de la responsabilidad administrativa, civil o penal correspondiente. La caducidad determina la reversión al Estado de la concesión, desde el momento de la inscripción de la cancelación del título correspondiente.

Por ello, su aplicación está condicionada al cumplimiento de los presupuestos señalados en la Ley Forestal y de Fauna Silvestre, su reglamento y demás normas complementarias así como a la previa realización de un procedimiento administrativo sancionador revestido de todas las garantías que aseguren un debido procedimiento y disminuyan la posibilidad de la emisión de una resolución arbitraria.

Así, la declaración de la caducidad de un derecho de aprovechamiento en el Perú no constituye una sanción sino más bien una expresión del ius imperium del Estado en su búsqueda de lograr un manejo sostenible de los recursos forestales. Este razonamiento va a encontrar sustento cuando se observa que en la normativa su regulación recibe un tratamiento especial estableciéndose que su declaración va a ser consecuencia en algunos casos de la comisión de una infracción que viene aparejada de una sanción, por lo que no puede ser considerada como tal por cuanto tener un razonamiento contrario impediría su aplicación e implicaría la violación del principio-derecho del Non bis in idem, al establecer más de una sanción por un mismo hecho, en un mismo proceso y en una misma vía (por ejemplo cuando se establece la sanción de pago de multa por el incumplimiento de los términos del contrato), algo que no es querido por el legislador ni está en el espíritu de la norma porque de ser así estaría expresado en la parte correspondiente a las sanciones como una sanción accesoria, tal como sucede en el Código Penal con las penas que van aparejadas a la pena privativa de libertad; al contrario, y yendo en la línea de pensamiento antes expresada, el Reglamento de la Ley Forestal y de Fauna Silvestre en su artículo $91^{\circ}$ prescribe que la declaración de caducidad de los derechos de concesión forestal con fines maderables no exime a los titulares de los mismos de las responsabilidades civiles, administrativas o penales a que hubiere lugar, hasta que haya concluido el plan de cierre de la concesión. 
Con ello se reafirma la intención de considerar a la caducidad del título habilitante no como sanción sino como una consecuencia de un determinado hecho que no necesariamente es causal de infracción, debiendo valorarse como una medida complementaria a la sanción impuesta y que busca ya no resarcir o corregir el daño sino evitar que se produzcan nuevos daños, al extinguir el derecho que fue invocado para producirlo. Es más, la declaración de la caducidad no está vinculada indefectiblemente a la existencia de un daño al recurso o una afectación directa al bien jurídico objeto del contrato, como sucede generalmente con la sanción administrativa, sino al mero incumplimiento contractual, como sucede con la falta de pago por derecho de aprovechamiento, en donde no hay daño al recurso sino una afectación monetaria al erario nacional, o la falta de presentación o de aprobación de los instrumentos de gestión que por sí mismos no causan daño al recurso.

En esa medida, se debe afirmar que la caducidad, al no constituir una sanción sino una suerte de medida complementaria producto de la voluntad unilateral del Estado que tiene por objeto salvaguardar un bien público como es el patrimonio forestal, puede perfectamente basarse no solo en un mismo hecho sino que puede acompañar a la sanción impuesta cuando aquel constituye también una infracción administrativa, lo cual obviamente implica una doble valoración por cuanto no toda infracción es causal de caducidad o va a determinar su declaración aunque sea causal, por cuanto en la infracción administrativa para su establecimiento prima siempre la determinación de la existencia del presupuesto de hecho, siendo la gravedad o la intencionalidad criterios para la aplicación de la multa pero para la declaración de la caducidad no, porque para la declaración debe considerarse, además del presupuesto de hecho, su gravedad, no pudiendo desligarse porque la determinación de la gravedad es la que determina finalmente si debe o no declararse lo que no sucede con la infracción.

El mismo razonamiento se aplica para la posibilidad de declarar la prescripción de la potestad de declararla. En general, conforme lo prescribe la Ley de Procedimiento Administrativo General Ley $\mathrm{N}^{\circ} 27444$, la prescripción de la acción sancionatoria de la administración ocurre cuando transcurren cuatro años sin que la sanción administrativa se haya impuesto, si el plazo no se establece en una norma especial, el cual, sin embargo, no puede exceder el dado por la ley general. La prescripción de la potestad sancionadora de la administración opera en el Perú ${ }^{26}$ únicamente para la imposición de sanciones administrativas, pero como la caducidad no es una infracción, entonces se considera que el plazo antes señalado (cuatro años) no se aplica, y al no establecerse ninguno en la normatividad vigente, se considera que esta atribución es imprescriptible.

26 A diferencia de España, en donde opera no solo para iniciar el procedimiento y sancionar sino también para concluir el procedimiento mismo. 
Al respecto, es necesario señalar que la imprescriptibilidad no es exclusiva del Derecho Administrativo Ambiental en el Perú sino que se presenta en el Derecho comparado, como por ejemplo en el Derecho español; tampoco lo es del Derecho Administrativo, porque en el Derecho Penal en general existe la tendencia, por lo menos en el Perú, a considerar la imprescriptibilidad para la persecución de delitos diferentes a los de lesa humanidad, y en Derecho Civil se presenta para la posibilidad de interponer demandas como las referidas a algunos derechos patrimoniales o vinculados a la filiación y reconocimiento de paternidad. En el caso de la imprescriptibilidad del derecho para declarar la caducidad del derecho de aprovechamiento, radica en la naturaleza de la caducidad como potestad discrecional del Estado y fruto de una declaración unilateral así como en el interés tutelado. En el caso de la concesión de bienes públicos, se debe entender siempre que el titular de dichos bienes es la Nación y que el Estado es el que recibe, por mandato del Constituyente, el encargo de administrarlos, pudiendo entregar a los privados este poder para ser ejercido de manera restringida. Esta situación implica la posibilidad, como sucede en un contrato privado, de poder extinguir el contrato unilateralmente en cualquier momento por causal sobreviniente generada en un incumplimiento lo suficientemente grave como para poner en riesgo al bien mismo, como sucede por ejemplo en la resolución de un contrato de arrendamiento por falta de pago. Esta posibilidad implica la existencia de causales que de verificarse implican, por ese solo hecho, la necesidad de extinguir el derecho para asegurar la preservación del recurso allí cuando la administración se percate de su materialización, tal como sucede con la falta de pago de derecho de aprovechamiento, el cambio de uso del suelo sin autorización o el mismo incumplimiento de las condiciones establecidas para las modalidades de manejo.

Esta atribución del Estado no puede estar sometida a la presión del tiempo porque se puede dar el caso de que la causal sea detectada cuando el plazo para infraccionarla administrativamente ha prescrito. ${ }^{27}$ Razonamiento contrario invitaría al concesionario a buscar cualquier elemento a fin de demorar la acción fiscalizadora de la administración buscando ampararse en el transcurso del tiempo para prolongar indebidamente la vigencia de su título, implicando además la abdicación voluntaria del Estado a su función tuitiva del patrimonio nacional, lo cual no es admisible.

De esa manera, la declaración de caducidad no debe entenderse como un castigo — como sucede con la sanción administrativa o penal - sino como una medida de prevención para evitar la continuidad del daño generado o del perjuicio causado, según sea el caso; al no ser un castigo, no cae en el contenido de la persecutoriedad de la que está revestida la facultad punitiva del Estado que sí debe estar sometida a un plazo, sino que más bien termina siendo una medida preventiva que busca revertir al dominio del Estado los bienes que fueron

27 Este es el mismo razonamiento que sustenta la posibilidad — negada en el Perú— de que la posibilidad de declarar la nulidad de un acto administrativo no prescriba. 
entregados en custodia al concesionario para evitar que este los aproveche poniendo en riesgo su sostenibilidad, ocasionando con ello un perjuicio a toda la sociedad.

\section{Consideraciones para la declaración de la caducidad de un derecho de aprovechamiento forestal}

El procedimiento para declarar la caducidad del derecho de aprovechamiento, a pesar de ser una potestad discrecional del Estado, no está totalmente desregulado porque la legislación reglamentaria y procesal determina cómo es que la administración debe actuar a efectos de lograr la extinción del derecho otorgado por causal sobreviniente a su celebración. Para analizar este extremo, es necesario partir de la consideración establecida en la misma Ley de Procedimiento Administrativo Ley $\mathrm{N}^{\circ} 27444$ cuando señala que la razón de ser de la administración pública es salvaguardar el interés general respetando los derechos fundamentales de las personas, la Constitución y la ley, lo cual siempre debe llevar a considerar como finalidad teleológica de la acción administrativa a la persona y el respeto a su dignidad, tal como lo prescribe el artículo $1^{\circ}$ de la Constitución Política del Estado.

Así, se debe considerar lo señalado en el artículo $230^{\circ}$ de la Ley de Procedimiento Administrativo General cuando señala que el procedimiento sancionador está guiado, entre otros, por el principio de razonabilidad, el cual señala que las sanciones aplicadas deben considerar los siguientes criterios para imponerlas: a) la gravedad del daño al interés público y/o bien jurídico protegido, b) el perjuicio económico causado, c) la repetición y/o continuidad en la comisión de la infracción, d) las circunstancias de la comisión de la infracción, e) el beneficio ilegalmente obtenido y f) la existencia o no de intencionalidad en la conducta del infractor.

Todas estas consideraciones, aplicables al establecimiento de una sanción con el objeto de limitar la discrecionalidad de la administración, pueden ser perfectamente aplicables a efectos de declarar la caducidad de un derecho, y en realidad deben ser observadas por cuanto en el proceso sancionador la caducidad del título habilitante es declarada siguiendo el mismo íter procesal establecido para determinar la existencia de responsabilidad por infracción a la ley forestal.

Por tanto, debe considerarse la necesidad de respetar los extremos contenidos en el debido procedimiento, expresión en vía administrativa del principio del debido proceso consagrado en la Constitución Política del Estado.

El debido proceso es el conjunto de garantías indispensables para que un proceso en el cual se va a tomar una decisión pueda ser considerado justo.

En realidad, el debido proceso no se explica ni tiene contenido si no se considera como el respeto a un conjunto de garantías que en este caso tiene el administrado y que 
buscan evitar la generación de una resolución administrativa abusiva, como resultado de una administración de poder estatal sin limitación alguna. Así, el debido proceso en sede administrativa va a ser entendido como el respeto a todos los derechos, atribuciones y garantías que tiene el administrado así como el cumplimiento de las obligaciones que tiene que cumplir la administración en el marco del respeto a los derechos fundamentales y a la dignidad del administrado en cuanto persona humana (considerando a las personas jurídicas como portadoras de derechos en la medida que estas son una prolongación de las personas físicas).

Existen dos modalidades de debido proceso: el adjetivo y el material. El debido proceso adjetivo o procesal implica el cumplimiento de las formalidades del proceso, las mismas que se encuentran señaladas en la Constitución y desarrolladas en las normas procesales pertinentes en cada caso concreto. ${ }^{28}$ En cambio, el debido proceso material implica la emisión de una sentencia ajustada a Derecho, es decir, la realización de un proceso justo. Ello implica que se cumplan con criterios mínimos de razonabilidad, de proporcionalidad, de equidad, que permitan vincular el debido proceso, no solo con el cumplimiento de requisitos formales, sino además con la satisfacción de la justicia como valor necesario para obtener la resolución de los conflictos y la paz social. ${ }^{29}$

En esa medida, siguiendo a Morón Urbina,${ }^{30}$ se tiene que el debido proceso comprende, entre otros, el derecho del administrado a exponer sus argumentos, el derecho a ofrecer y producir prueba (que comprende el derecho a presentar medios de prueba, a exigir que la administración produzca y actúe los medios ofrecidos, a contradecir las pruebas de cargo, y la de controlar la actuación probatoria que se realice durante la instrucción, y a que se valore la prueba aportada), el derecho a obtener una decisión motivada y fundada en Derecho (derecho a que las resoluciones del procedimiento sancionador hagan expresa consideración de los argumentos de Derecho y de hecho que los motivan y, en particular, de la graduación de la sanción a aplicarse), el derecho a no ser discriminado en el procedimiento administrativo, el derecho de acceso a la autoridad, el derecho a participar en el proceso, el derecho a la autoridad predeterminada por ley, el derecho al desdoblamiento de las instancias de instrucción y sanción, el derecho a ser notificado previamente de decisiones concernientes, el derecho a probar, el derecho al ofrecimiento y actuación de pruebas de parte, el derecho al control de la prueba de cargo, el derecho a la valoración de la prueba de cargo, el derecho a no declarar en su contra, el derecho a obtener las medidas cautelares de protección temporal, el derecho a un procedimiento sin dilaciones indebidas, el derecho a la presunción de inocencia, el derecho

28 Christian Guzmán Napurí. Tratado de la Administración Pública y del Procedimiento Administrativo. Lima: Caballero Bustamante ED, 2011, p. 805.

29 Christian Guzmán Napurí . Op. cit. p. 806.

30 Juan Carlos Morón Urbina. Comentarios a la Ley de Procedimiento Administrativo General. 5ta. ed. Lima: Gaceta Jurídica Ed., 2006, pp. 641-642. 
de acceso a la justicia, el derecho de acceso al expediente, el derecho a que las actuaciones gravosas sean lo menos gravosas posible, el derecho de defensa.

A continuación, se desarrollan únicamente tres elementos que se deben considerar a efectos de poder limitar la discrecionalidad de la administración para declarar la caducidad de un derecho de aprovechamiento forestal.

\section{a) Principio de verdad material}

El principio de verdad material consagrado en el artículo 1.11 de la Ley de Procedimiento Administrativo General Ley No $27444^{31}$ obliga a la autoridad que instruye el procedimiento a verificar los hechos que fundamentan sus decisiones, en este caso sus resoluciones. Esta verificación implica la necesidad de probar las imputaciones para establecer la certeza de su comisión; así, realizada la imputación, la administración debe agotar todos los medios necesarios tendientes a verificar las afirmaciones realizadas en el desarrollo del procedimiento, hayan o no sido invocadas por el administrado.

En ese sentido, debe recordarse que en el ámbito del Proceso Administrativo Sancionador la presunción de inocencia es un principio-derecho de arraigo constitucional que guía todo su desarrollo, lo cual implica que la carga de la prueba de la existencia de los elementos del tipo infractorio y su autoría corren a cargo de la Administración, ${ }^{32}$ esto es que para aplicar una sanción o una medida complementaria es necesario que previamente se haya podido determinar que los elementos que figuran en el expediente tengan un contenido suficientemente incriminatorio, de manera que puedan acreditar la realidad de los hechos concretos con sus circunstancias agravatorias relevantes y la participación del administrado en los mismos. Así, toda resolución sancionadora, sea penal o administrativa, requiere a la par certeza de los hechos imputados, obtenida mediante pruebas de cargo, y certeza del juicio de culpabilidad sobre esos mismos hechos. ${ }^{33}$ Esto implica que todos los actos y resoluciones de la Administración han de fundarse en las situaciones fácticas y demostradas por la misma administración, lo cual aleja la posibilidad de resolver sobre la base de indicios. Tal como lo señala Nieto, la fortaleza constitucional de la presunción de inocencia la hace inmune a la contrapueba realizada por simples indicios o conjeturas que no tienen nunca fuerza bastante para romper aquella, ${ }^{34}$ lo cual se refuerza con lo dicho por el Tribunal Supremo Español cuando señala queen el ámbito del Derecho Administrativo Sancionador,

31 Ley de Procedimiento Administrativo General Ley No 27444.

1.11. Principio de verdad material.- En el procedimiento, la autoridad administrativa competente deberá verificar plenamente los hechos que sirven de motivo a sus decisiones, para lo cual deberá adoptar todas las medidas probatorias necesarias autorizadas por la ley, aun cuando no hayan sido propuestas por los administrados o hayan acordado eximirse de ellas.

32 Se considera que para los efectos de la aplicación de la caducidad se aplican los mismos criterios que para la determinación de la existencia de infracción administrativa.

33 Manuel Gómez Tomillo e Iñigo Sanz Rubiales. Derecho Administrativo Sancionador. Teoría general y práctica del Derecho Penal Administrativo. 2da. Ed. Madrid: Ed. Aranzadi, 2010, p. 824.

34 Alejandro Nieto. Derecho Penal Sancionador. 4ta. Ed. Madrid: Tecnos, 2004, p. 422. 
a diferencia de lo que ocurre en el procedimiento penal, no es procedente acudir a indicios racionales o valoraciones de conciencia para dar por probada una infracción administrativa, viniendo condicionada la legalidad de las sanciones administrativas por la tipicidad de la falta y por la prueba concluyente e inequívoca de que el sancionado es responsable de aquella. ${ }^{35}$

Es más, debe considerarse que para demostrar la responsabilidad del infractor en la comisión de hechos que deriven también en una causal de caducidad vinculados al cumplimiento de obligaciones contractuales debe probarse in situ, allí en donde la causal no pueda probarse suficientemente con la documentación existente, tal como sucede por ejemplo con la falta de pago del derecho de aprovechamiento o el incumplimiento de la presentación de los instrumentos de gestión dentro de los plazos otorgados por la administración, en donde obviamente no es necesario recurrir a un instrumento exterior para comprobar la existencia de la causal; sin embargo, cuando se habla por ejemplo del incumplimiento de las condiciones establecidas para las condiciones del contrato o el cambio de uso del suelo sin autorización, será necesario demostrar en el campo dicha imputación, lo cual lleva a considerar que el principal medio probatorio en este caso es el acta de supervisión mas no el único admisible, por cuanto se admiten otros medios probatorios derivados no de una inspección física sino por ejemplo de otros informes administrativos emitidos por otras autoridades (que tienen valor legal y calidad de declaración jurada, sin llegar a ser pruebas preconstituidas) o de elementos de análisis y evaluación tecnológica de comprobada validez, como por ejemplo las fotos satelitales o los análisis de laboratorio, los que sí pueden, llegado el momento, complementar la información existente para poder determinar una conclusión resistente jurídicamente.

Normalmente, se considera que el medio probatorio es el informe de supervisión. Dicha consideración es errada por cuanto el informe solo contiene conclusiones derivadas de la supervisión y que constan en el acta correspondiente. Una conclusión no puede ser una prueba por sí sola sino que depende para su validez de sus considerandos y elementos que sirven para arribar a ella; por tanto, las meras afirmaciones contenidas en los informes no son suficientes para responsabilizar y no contienen la fuerza suficiente para destruir por sí solas la presunción de inocencia porque es el acta la que debe contener los elementos materiales a considerar para declarar la caducidad. Además, el acta, en virtud de su naturaleza, debe necesariamente contener únicamente lo que se verifica, no pudiendo contener otras apreciaciones, las que, de existir, se consideran como no puestas, teniendo validez solo lo verificado objetivamente.

Cabe analizar si le compete a la Administración la tarea de probar la existencia de los hechos que conllevan a declarar la caducidad. Es que en materia forestal el administrado está en mejor posición para probar la legalidad de su acto por cuanto solo él sabe cómo es que ha realizado la actividad. La supervisión de campo determina generalmente la existencia

35 Sentencia del Tribunal Supremo Español del 5 de febrero de 1990. En: Alejandro Nieto. Op. cit. p. 422. 
de incoherencias entre lo hallado y lo declarado, y estas determinan la presunción de la existencia de incumplimientos contractuales como consecuencia de la mala realización del aprovechamiento, por lo que le toca al administrado demostrar que dichas incoherencias no son tales mediante la presentación de elementos de carácter técnico que demuestre lo contrario; en ese sentido, si bien es cierto que la Administración va a tener la carga de la prueba para probar la existencia de la causal, el administrado debe presentar elementos para desvirtuar el presunto incumplimiento. Un razonamiento contrario implicaría la posibilidad de la Administración de declarar la caducidad por incumplimiento de las condiciones establecidas para la modalidad de aprovechamiento, por cuanto generalmente solo puede determinar que los volúmenes movilizados provienen de árboles no declarados o autorizados para su talado mas no de dónde proviene la madera ilegal.

\section{b) Principio de razonabilidad}

El artículo IV .1.4 de la Ley de Procedimiento Administrativo General Ley No 27444 prescribe que el Procedimiento Administrativo está guiado, entre otros, por el llamado principio de razonabilidad, definido de la siguiente manera:

Las decisiones de la autoridad administrativa, cuando creen obligaciones, califiquen infracciones, impongan sanciones o establezcan restricciones a los administrados, deben adaptarse dentro de los límites de la facultad atribuida y manteniendo la debida proporción entre los medios a emplear y los fines públicos que deba tutelar, a fin de que respondan a lo estrictamente necesario para la satisfacción de su cometido.

La aplicación de este principio en la imposición de una sanción implica, en opinión de Alejandro Nieto, la adecuación de la medida aplicada para obtenerlo, la necesidad de establecer criterios cuyo tratamiento permita conocer el grado de perjudicialidad o dañosidad de cada medida de las de posible adopción, o la concordancia entre la entidad de dicha medida y la importancia del objetivo que la justifica. ${ }^{36}$

El mismo autor, citando a Zornoza, señala que este principio tiene una doble funcionalidad, actuando por un lado como criterio para la selección de comportamientos antijurídicos merecedores de la tipificación como delitos o infracciones (actuación legislativa), y por otro como límite de la actividad administrativa de determinación de las sanciones "sin que por tanto exista posibilidad alguna de opción libre, sino una actividad vinculada a la correspondencia entre infracción y sanción" (labor de aplicación). ${ }^{37}$

36 Alejandro Nieto. Op. cit. p. 350.

37 Ibid. 
Esto implica, conforme lo señala la Ley española 30/1992 — que regula el procedimiento administrativo en dicho país y que es la fuente directa de la ley $\mathrm{N}^{\circ} 27444$ - que en las determinaciones normativas del régimen sancionador, así como en la imposición de sanciones por las Administraciones Públicas, se deberá guardar la debida adecuación entre la gravedad del hecho constitutivo de la infracción y la sanción aplicada, considerándose especialmente los siguientes criterios para la graduación de la sanción a aplicar: la existencia de intencionalidad o reiteración, la naturaleza de los perjuicios causados y la reincidencia. ${ }^{38}$

La aplicación del principio de razonabilidad en un acto de gravamen implica, a decir de Morón Urbina, la existencia del cumplimiento de dos requisitos:

a) Adoptarse dentro de los límites de la facultad atribuida, o sea, cumplir y no desnaturalizar la finalidad para la cual fue otorgada la competencia para emitir el acto de gravamen, $y$

b) Mantener la proporción entre los fines y los medios, haciendo que la decisión adoptada sea proporcional a la finalidad perseguida por la norma legal. ${ }^{39}$

Todos estos presupuestos, aplicables al establecimiento de una sanción, deben también ser aplicables para declarar la caducidad de un derecho, y en realidad deben ser observados por cuanto en el proceso sancionador del OSINFOR la caducidad del título habilitante es declarada en el mismo procedimiento por el que se establece la responsabilidad por infracción a la ley forestal.

\section{c) Principio de proporcionalidad}

La aplicación del principio de proporcionalidad conlleva que la sanción que se impute a una infracción dada implique la congruencia entre la infracción cometida, los fines a obtener con la sanción y el efecto de la misma. Esto quiere decir que cuando la administración tenga varias posibilidades de limitación de un derecho, se debe elegir a la menos gravosa respecto del derecho fundamental a limitar, siendo necesario, finalmente, que el grado de afectación al derecho se encuentre acorde con el nivel de obtención de la finalidad perseguida con la limitación. Para la aplicación de una sanción, es necesario que se cumpla con las tres dimensiones de la proporcionalidad, que se refieren al juicio o principio de idoneidad o adecuación, al principio de necesidad, así como al principio de proporcionalidad en sentido estricto. El primero de ellos implica que la sanción aplicada sea adecuada a la finalidad perseguida con la sanción, vale decir, que efectivamente el resultado de la misma constituya la satisfacción de dicha finalidad; asimismo, el criterio de necesidad refiere que la sanción

\footnotetext{
Ley 30/1992 Ley de Procedimiento Administrativo Común. Artículo 131.3

Juan Carlos Morón Urbina. Op. cit. p. 70.
} 
sea la menos gravosa posible ante la equivalencia en la obtención del resultado conforme al fin perseguido con la sanción. Finalmente, el criterio de ponderación implica comparar la afectación de los intereses del administrado a través de la sanción impuesta con la intensidad de la satisfacción del fin perseguido, a fin de determinar si dicha afectación se encuentra debidamente justificada. ${ }^{40}$

En esa medida, para la declaración de la caducidad —utilizando el criterio usado para imponer una sanción administrativa - se debe considerar la aplicación del principio de proporcionalidad, lo que demanda tres consideraciones:

- Si la declaración de caducidad es una medida idónea y satisface la finalidad de su imposición, es decir, si la medida va a evitar que el daño al medio ambiente continúe;

- Aplicación del principio de necesidad referido a que la medida a imponer sea la menos gravosa posible ante la equivalencia en la obtención del resultado conforme al fin perseguido con la sanción. Debe considerarse que la caducidad se declara ante situaciones extremadamente graves, y ello es porque termina siendo la última ratio en materia de administración de títulos habilitantes, porque implica la extinción del derecho. Aquí debe considerarse la posibilidad de que la imposición de otras medidas igualmente satisfagan la necesidad de sancionar la conducta materia de procesamiento y eviten, al mismo, tiempo su continuidad.

- Aplicación del principio de proporcionalidad en sentido estricto. Es necesario establecer si la declaración de la caducidad es compatible con el daño ocasionado y con el fin buscado al declararla.

Si bien es cierto una lectura ligera del artículo $18^{\circ}$ de la Ley Forestal y de Fauna Silvestre antes citado podría llevar a pensar que su aplicación es relativamente sencilla, no es así cuando se tiene que considerar la existencia de supuestos en los cuales la aplicación automática de la norma puede llevar a la Administración hacia un exceso de punición al declarar la caducidad del derecho si no se adopta un criterio de proporción entre el incumplimiento y la medida a imponer, algo que no siempre es sencillo, especialmente en materia forestal, donde es sumamente complejo valorizar el perjuicio ocasionado o determinar la intención del administrado; y es que, como lo señala Nieto, el concepto de proporcionalidad, por su propia naturaleza, resulta difícilmente concretable en términos de gran especificación y singularidad, hasta el punto de que su aplicación, en último término, tiene que venir fundamentada en una apreciación conjunta de las circunstancias objetivas y subjetivas que integran el presupuesto de hecho sancionable. Esta apreciación se torna difícil cuando no existen criterios uniformes o cuando no hay vallas de imposición que determinen a partir de dónde es posible establecer una mera sanción o determinar, además, como en el caso de la caducidad, la extinción del

40 Christian Guzmán Napurí. Op. cit. pp. 807-808. 
derecho. Así, la Administración puede optar por dos posibilidades: 1) dejar su aplicación totalmente en manos de la Administración, limitándose el legislador solo a señalar la causal, quedando en la autoridad administrativa la valoración de la conducta; o 2) establecer mediante una fórmula legislativa todas las causales y además los criterios para establecerlas eliminando la discrecionalidad en la búsqueda de una mayor garantía para el administrado. En el Perú, como se ha explicado anteriormente, la fórmula vigente es la primera porque existen causales abiertas para determinar la gravedad de la conducta y extinguir el derecho, lo cual ha sido bastante criticado, por lo que la nueva legislación opta por un camino intermedio al fijar en la norma legal la causal y al mismo tiempo establecer en la norma reglamentaria la necesidad de que los criterios sean fijados por la Administración pero mediante normas o directivas de aplicación general, con lo que en la práctica se elimina la discrecionalidad o se reduce a su mínima expresión.

Por otro lado, como se ha señalado líneas arriba, un criterio para establecer la responsabilidad y determinar la sanción es la intencionalidad con la que el agente ha actuado. En materia ambiental, sin embargo, prima el criterio de que la sanción se debe establecer sin considerar la intención sino midiendo el resultado de la conducta, es decir, aplicando el criterio de la existencia de responsabilidad objetiva.

La responsabilidad objetiva como criterio para aplicar la sanción administrativa no es única del sector ambiental; Napurí, por ejemplo, señala que en general en el Derecho Administrativo Sancionador prima la responsabilidad objetiva.

La Ley Forestal y de Fauna Silvestre vigente no hace referencia a la aplicación de un criterio de responsabilidad objetiva para el establecimiento de sanciones por la comisión de infracciones administrativas, únicamente hace referencia a que estas se aplican sin perjuicio de las acciones civiles o penales a que hubiera lugar. ${ }^{41}$

El establecimiento del criterio para determinar el régimen de responsabilidad es dado en el artículo $144^{\circ}$ de la Ley General del Ambiente Ley $\mathrm{N}^{\circ}$ 28611, en donde se señala que la responsabilidad derivada del uso o aprovechamiento de un bien ambientalmente riesgoso o peligroso, o del ejercicio de una actividad ambientalmente riesgosa o peligrosa, es objetiva. Esta responsabilidad obliga a reparar los daños ocasionados por el bien o actividad riesgosa, lo que conlleva asumir los costos contemplados en el artículo $142^{\circ}$, precedente, y los que correspondan a una justa y equitativa indemnización; los de la recuperación del ambiente afectado, así como los de la ejecución de las medidas necesarias para mitigar los efectos del daño y evitar que este se vuelva a producir. ${ }^{42}$

$41 \quad$ Ley Forestal y de Fauna Silvestre Ley 27308. Artículo 39.

42 Ley General del Ambiente

Artículo $142^{\circ}$.- De la responsabilidad por daños ambientales 
Esta posición ha sido ratificada recientemente con la aprobación por parte del OEFA ${ }^{43}$ —organismo rector de nivel nacional en materia de fiscalización ambiental— de las Reglas Generales sobre el Ejercicio de la Potestad Sancionadora del OEFA, ${ }^{44}$ en donde se señala en su punto sexto que de conformidad con lo establecido en el Artículo $18^{\circ}$ de la Ley del Sistema Nacional de Evaluación y Fiscalización Ambiental, la responsabilidad administrativa en materia ambiental es objetiva.

En aplicación del principio de presunción de licitud (presunción de inocencia), la autoridad competente del OEFA debe acreditar la existencia de la infracción administrativa, es decir, verificar el supuesto de hecho del tipo infractor. Sin embargo, el administrado imputado puede eximirse de responsabilidad si acredita la fractura del nexo causal, sea por caso fortuito, fuerza mayor o hecho determinante de tercero.

\section{CONCLUSIONES}

1. El contrato de concesión de bienes públicos es un acto administrativo de naturaleza mixta en el que la voluntad del Estado tiene una posición de superioridad sobre la del concesionario, lo cual le permite cambiar las condiciones del contrato antes de su celebración o después de esta.

2. La caducidad de la concesión no es una sanción, es una expresión unilateral de la voluntad del Estado en la búsqueda de salvaguardar el interés público marcado por la preservación de un recurso patrimonio de la Nación. En esa medida, no prescribe y puede acompañar a la imposición de una sanción como consecuencia del mismo hecho, cuando este configura también una infracción administrativa.

3. La caducidad, a pesar de ser una declaración unilateral, no puede estar desprovista de las garantías que tiene el debido proceso en su expresión administrativa (debido procedimiento), y ante la inexistencia de una normativa específica pueden ser de aplicación los principios establecidos para la imposición de sanciones administrativas, sin que ello la convierta en una de esa naturaleza.

142.1. Aquel que mediante el uso o aprovechamiento de un bien o en el ejercicio de una actividad pueda producir un daño al ambiente, a la calidad de vida de las personas, a la salud humana o al patrimonio, está obligado a asumir los costos que se deriven de las medidas de prevención y mitigación de daño, así como los relativos a la vigilancia y monitoreo de la actividad y de las medidas de prevención y mitigación adoptadas.

142.2 Se denomina daño ambiental a todo menoscabo material que sufre el ambiente y/o alguno de sus componentes, que puede ser causado contraviniendo o no disposición jurídica, y que genera efectos negativos actuales o potenciales.

43 Organismo de Evaluación y Fiscalización Ambiental.

44 Aprobado mediante Resolución de Consejo Directivo No 038-2013-OEFA/CD publicada en el Diario Oficial El Peruano, el 18 de setiembre de 2013. 


\section{REFERENCIAS}

- Arana Rodríguez, Jaime. "Reflexiones sobre la caducidad en el Derecho Público". Separata de la Revista Aragonesa de Administración Pública, 5, 1994, p. 340-355.

- Báez Martínez, Roberto. Manual de Derecho Administrativo. México: Ed. Trillas, 1990.

- Calafell, Jorge. "Teoría general de la concesión". Jurídica, pp.215-228. Recuperado el 25 de septiembre de 2013 desde http://www.juridicas.unam.mx/publicallibrev/rev/jurid/ cont/26/pr/pr19.pdf

- Cano Jiménez, Sergio. "Estudio sobre la concesión administrativa y su definición”. Revista del Poder Judicial del Estado de Guanajuato, 1 (1964).

- De la Fuente Alonso, Alejandro. "La naturaleza jurídica de la concesión administrativa". Recuperado desde http://portal.veracruz.gob.mx/pls/portal/docs/page/colver/difusion/revista_ conciencialrevistano.8/2.-alejandro\%20de\%20la\%20fuente\%20alonso.pdf

- Dromi, Roberto. Derecho Administrativo. Décima edición. Buenos Aires, 2004.

- Escola, Héctor. El interés público como fundamento del Derecho Administrativo. Buenos Aires: Ed. Depalma, 1989.

- Fernández Vásquez, Emilio. Diccionario de Derecho Público. Buenos Aires: Astrea, 1981.

- Gómez Tomillo, Manuel y Sanz Rubiales, Iñigo. Derecho Administrativo Sancionador. Teoria general y práctica del Derecho Penal Administrativo. 2da. Ed. Madrid: Ed. Aranzadi, 2010.

- Guzmán Napurí, Christian. Tratado de la Administración Pública y del Procedimiento Administrativo. Lima: Caballero Bustamante ED., 2011.

- Morón Urbina, Juan Carlos. Comentarios a la Ley de Procedimiento Administrativo General. 5ta. ed. Lima: Gaceta Jurídica Ed., 2006.

- Nieto, Alejandro. Derecho Penal Sancionador. 4ta. Ed. Madrid: Tecnos, 2004, p. 422.

- Pérez de León, Enrique. Notas de Derecho Constitucional y Administrativo. 14 ed. México: Porrúa, 1993.

- Serra Rojas, Andrés. Derecho Administrativo. T. 1., 9na. ed. México, 1979. 